\title{
Isolation and Molecular Identification of a Siderophore Producing Bacterium and its Antagonistic Effect Against Fusarium oxysporum f. sp. cubense Tropical Race 4
}

\author{
Yu Rou Ch'ng, Christina Seok Yien Yong*, Siti Norhidayah Othman, Nur Ain \\ Izzati Mohd Zainudin and Muskhazli Mustafa
}

Department of Biology, Faculty of Science, Universiti Putra Malaysia, 43400, Serdang, Selangor, Malaysia

\begin{abstract}
Bananas are one of the world's most consumed fruits. Developing countries in the Global South depend on bananas for food security and livelihoods. Still, the banana industry also drives a multinational trade worth billions of US dollars. In addition, banana plants also hold cultural and religious significances in many Asian countries. However, banana production faces several challenges, and one of the major issues is the Fusarium wilt disease caused by the fungus Fusarium oxysporum f. sp. cubense Tropical Race 4 (Foc TR4). This disease threatens numerous banana cultivars, including the Cavendish, the most traded banana cultivar. Therefore, the objective of this study was to find effective measures to control the spread of this disease through antagonistic soil bacteria. This study isolated 14 fluorescent, siderophore-producing bacteria with in vitro inhibition rates of 21.73$50.38 \%$ against Foc TR4 from the soil surrounding banana plants. Most of the isolates were identified as Pseudomonas spp. via $16 \mathrm{~S}$ rRNA sequencing, and phylogenetic analysis based on 16s rRNA sequences

ARTICLE INFO

Article history:

Received: 28 September 2021

Accepted: 6 December 2021

Published: 24 January 2022

DOI: https://doi.org/10.47836/pjtas.45.1.11

E-mail addresses:

jcyrwrites@gmail.com (Yu Rou Ch'ng)

chrisyong@upm.edu.my (Christina Seok Yien Yong)

dy.othman@gmail.com (Siti Norhidayah Othman)

ainizzati@upm.edu.my (Nur Ain Izzati Mohd Zainudin.)

muskhazli@upm.edu.my (Muskhazli Mustafa)

*Corresponding author

showed clustering of isolates congruent with the results of similarity searches. Three isolates that exhibited relatively higher antagonistic activity against Fusarium oxysporum f. sp. cubense compared to other isolates were JBAA132 (50.38\%), K2B131 (46.28\%), and KTP231 (45.38\%). Isolate JBAA132 displayed differences in biochemical characteristics compared to its closest match (Pseudomonas aeruginosa
\end{abstract}


type strain DSM50071). It also demonstrated nitrogen-fixing and phosphate solubilising properties common to plant growth promoters. Therefore, isolate JBAA132 may be further explored as a potential biocontrol agent in curbing the spread of Foc TR4.

Keywords: Biological control, Foc TR4, Fusarium wilt, Panama disease, plant growth promoter, Pseudomonas aeruginosa, siderophore

\section{INTRODUCTION}

Bananas are cultivated in more than 135 countries and are a staple food for many developing nations in Africa and Asia. Banana production was valued at 38 billion USD in 2018 and had an export value of 14.7 billion USD in 2020 (Workman, 2021). However, the production of bananas is severely threatened by Panama disease, also known as Fusarium wilt, caused by the fungus Fusarium oxysporum f. sp. cubense (Foc) (ProMusa, n.d.). Foc is classified into distinct races according to the banana varieties they infect, namely races 1, 2, 3, and 4. Foc Race 1 affected the Gros Michel banana and decimated plantations across Central America during the 1950s, prompting farmers to switch to the Cavendish because it was resistant to Foc Race 1 (Ploetz, 2005). However, a new and more virulent strain of Foc emerged in the 1970s, infecting the Cavendish bananas in Taiwan (Su et al., 1986). This new strain of Foc termed Foc Tropical Race 4 (TR4) can infect Musa spp. that is susceptible to Foc Race 1 and Race 2 in addition to the Cavendish. Furthermore, vegetative propagation of commercial banana plants results in daughter plants that are clones of the parent plant and are susceptible to the same disease. Increasing globalisation and the worldwide trading of bananas have also caused the Fusarium wilt to spread rapidly. The losses continue to rise as current prevention and management measures are ineffective and insufficient to control the disease (Scheerer et al., 2018). As such, Foc TR4 poses a serious threat to global banana production and food security (Food and Agriculture Organization of the United Nations [FAO], 2019).

Fusarium oxysporum f. sp. cubense TR4 is an ascomycete that reproduces asexually via microconidia, macroconidia, and chlamydospores (Ghag et al., 2015). According to VanderMolen et al. (1987), infection by its spores causes the host plant to form tyloses that gel up the xylems. The occlusion of the xylem prevents the host from transpiration and water transport, eventually killing the plant. Fusarium wilt is extremely difficult to control because the spores are durable and can persist in the soil for up to 30 years (Agrios, 2005; Hennessy et al., 2005). Therefore, finding reliable and efficient prevention methods is crucial for the survival of the banana industry and the livelihoods of communities that rely on banana production. While the development of disease-resistant cultivars is highly desirable, it is costly and time-consuming (Dita et al., 2018; Zuo et al., 2018). On the other hand, fungicides and sterilants have limited efficacy and are considered unsustainable due to the possible adverse 
effects on human health and the ecosystem (ProMusa, n.d.). Meanwhile, biological control or biocontrol agents reliant on an organism's natural functions to control a pest or a disease (Vincent et al., 2007) are progressively being investigated for the potential as a sustainable option to curb the spread of Foc TR4 (Sharma et al., 2017; Vincent et al., 2007).

Potential biocontrol candidates come from the genus Pseudomonas spp., ubiquitous Gram-negative, motile, flagellated, rod-shaped, and aerobic gammaproteobacteria (Jenny \& Kingsbury, 2018; Liao, 2006; Schroth et al., 2018; Weller, 2007). Members of Pseudomonas spp. have exhibited suppressive ability towards plant diseases such as the tomato disease caused by Pythium aphanidermatum (Jayaraj et al., 2007), pepper blight caused by Phytophthora capsici (Sang \& Kim, 2014), and pink snow mould of wheat caused by Microdochium nivale (Andersson et al., 2012). In addition, some strains of Pseudomonas spp. produce fluorescent pigments, such as pyoverdine or pyochelin during iron-deficit conditions, are observable under ultraviolet (UV) light (Budzikiewicz, 1996). These fluorescent pigments are iron chelators known as siderophores that allow the bacteria to scavenge ferric ions $\left(\mathrm{Fe}^{3+}\right)$ from the surroundings for DNA synthesis, oxygen transport, incorporation into proteins, and nitrogen fixation (Andrews et al., 2003; Cornelis \& Matthijs, 2007). Simeoni (1987) found that the germination of $F$. oxysporum f. sp. cucumerinum chlamydospores was inhibited when $\mathrm{Fe}^{3+}$ concentration in the soil reached $10^{-19} \mathrm{M}$ and $\mathrm{Fe}^{3+}$ concentrations of $10^{-22}$ to $10^{-27} \mathrm{M}$ produced optimal fungal inhibition. Meanwhile, Sayyed and Patel (2011) discovered that siderophore rich broth and supernatants exhibited strong antifungal activity against several types of fungi, including Aspergillus niger and $F$. oxysporum. These findings indicated that siderophore production and iron availability is strongly correlated to the antagonistic ability of Pseudomonas spp. against fungi.

Therefore, this study aimed to isolate potential biocontrol bacterial agents to suppress Foc TR4 by screening for fluorescent siderophore-producing bacteria and evaluating the antagonistic activities of the isolates against Foc TR4. Isolates exhibiting antagonistic activity were subsequently identified using 16s rRNA sequencing. In addition, the isolate that demonstrated more than $50 \%$ in vitro inhibition rate against Foc TR4 was further characterised using biochemical assays.

\section{MATERIALS AND METHODS}

\section{Isolation and Screening of Fluorescent Isolates}

Soil samples were collected from four points (north, south, east, west) at a depth of 20 $\mathrm{cm}$ around banana plants from Pahang and Selangor, Malaysia (Table 1). Healthy ( $\mathrm{N}=$ 44) and affected ( $\mathrm{N}=11)$ banana plants were selected randomly to increase the possibility of getting various bacterial samples. 
List of sampling sites and their corresponding coordinates

\begin{tabular}{|c|c|c|}
\hline Location & Coordinates & State \\
\hline Felda Lembah Klau, Raub & N341'29.454"; E1020'20.214" & Pahang \\
\hline Sungai Pelek, Sepang & $\mathrm{N} 2^{\circ} 40^{\prime} 15.4^{\prime \prime} ; \mathrm{E} 101^{\circ} 41^{\prime} 22.4^{\prime \prime}$ & Selangor \\
\hline Ladang Kongsi, UPM & N258'51.2"; E10142'45.4" & Selangor \\
\hline Kolej Kedua, UPM & N259'40.6"; E10142'20.6" & Selangor \\
\hline Kolej Tun Perak, UPM & N259'29.9"; E10142'26.8" & Selangor \\
\hline Jabatan Biology, UPM & N30'4.8204"; E10142’17.0604" & Selangor \\
\hline
\end{tabular}

The samples were stored at $4{ }^{\circ} \mathrm{C}$ and processed two weeks after collection. A modified protocol of Sudarma and Suprapta (2011) and Nawangsih and Purba (2013) was used for screening. First, samples collected from the four points of each plant were mixed, then one gram of the mixed soil sample was taken and diluted in $99 \mathrm{~mL}$ of sterilised water to make up to $100 \mathrm{~mL}$. After five minutes of agitation, the suspension of each mixed sample was used to prepare three spread plates on King's B agar (Pronadisa, Condalab, Spain) to isolate fluorescent bacteria, each with $1 \mathrm{~mL}$ of suspension. The plates were incubated at $25^{\circ} \mathrm{C} \pm 2$ for $48 \mathrm{~h}$, then viewed under UV light in an Enduro ${ }^{\mathrm{TM}}$ GDS-1302 gel documentation system (Labnet International, USA). Fluorescent colonies were picked and streaked on King's B agar, then incubated at $25^{\circ} \mathrm{C} \pm 2$ for $24 \mathrm{~h}$.

\section{Determination of Siderophore Production using Chrome Azurol S Overlay}

Blue Chrome Azurol S (CAS) dye was prepared according to Pérez-Miranda et al. (2007). A 7:3 mixture of blue CAS agar was prepared by slowly adding the dye to a $1 \%(\mathrm{w} / \mathrm{v})$ agarose solution, then poured onto the Petri dish containing $24 \mathrm{~h}$ colonies of a single isolate, and then incubated at $25{ }^{\circ} \mathrm{C}$ for $2 \mathrm{~h}$. The development of an orange-yellow zone indicated positive siderophore production. Therefore, colonies with positive siderophore production were chosen for the in vitro fungal antagonistic test. An uninoculated filter paper disc (4 $\mathrm{mm}$ ) in place of bacterial culture was used as a negative control. All experiments were repeated at least twice with three replicates for each isolate.

\section{In vitro Antagonistic Assay}

The Foc TR4 (culture collection number: 9888, isolated initially from Fusarium wilt infected banana, Kuala Terengganu, Terengganu) for the antagonistic test was provided by the Fusarium Collection Centre, Plant Pathology Laboratory, Universiti Sains Malaysia (USM). A dual culture in vitro antagonistic test was performed. First, a filter paper disc ( $4 \mathrm{~mm}$ ) was soaked in $24 \mathrm{~h}$ cultures of the isolate, then placed at $5 \mathrm{~cm}$ from a mycelial plug ( $4 \mathrm{~mm}$ ) of Foc TR4 on 
potato dextrose agar (PDA) (Merck, USA). After that, the plate was incubated at $25^{\circ} \mathrm{C}$ \pm 2 for 10 days. This assay was carried out in triplicate. An uninoculated filter paper disc was used as a negative control. The percentage of inhibition was calculated according to the formula provided in Chaiharn et al. (2009).

$$
\% \text { of inhibition }=\left(\frac{D_{c}-D_{t}}{D_{c}}\right) \times 100
$$

Where $\mathrm{Dc}=$ distance of fungal growth in the control plate when it was cultured opposite a blank disc, and Dt $=$ distance of fungal growth when it was cultured opposite a filter paper disc inoculated with the isolate. A one-way analysis of variance (ANOVA) was performed, followed by Tukey's honest significant difference (HSD) post-hoc test to determine if the inhibition rates were significantly different (GraphPad Prism version 9.2.0 for Windows, GraphPad Software, USA, www.graphpad.com). The isolates were then identified via molecular means.

\section{Molecular Identification of Bacterial Isolates}

The DNA of each isolate was extracted using the methods described in Nasiri et al. (2005) with slight modification by substituting the mentioned laundry powder with $25 \mathrm{mg} / \mathrm{mL}$ of enzymatic Daia washing powder (PT. Sayap Mas Utama, Indonesia). Amplification of the 16s rRNA region was performed on PCRmax Alpha Cycler (PCR Max, USA) using primers 16SF (5'-CGGTTACCTTGTTACGACTT-3') $\begin{array}{llllllll}\mathrm{a} & \mathrm{n} & \mathrm{d} & 1 & 3 & 8 & 7 & \mathrm{R}\end{array}$ (5'-GCCCGGGAACGTATTCACCG-3') obtained from Nawangsih and Purba (2013), and GoTaq ${ }^{\circledR}$ Flexi DNA Polymerase reagents (Promega, USA). In each $20 \mu \mathrm{L}$ reaction, it contained $2 \mu \mathrm{L}$ GoTaq $^{\circledR}$ buffer $(5 \mathrm{x}), 1 \mu \mathrm{L}$ magnesium chloride ( $25 \mathrm{mM}), 2 \mu \mathrm{L}$ dNTPs $(2 \mu \mathrm{M}), 2 \mu \mathrm{L}$ of each forward primer $(2 \mu \mathrm{M})$ and reverse primer $(2 \mu \mathrm{M}), 1 \mu \mathrm{L} \mathrm{GoTaq}^{\circledR}$ polymerase $(0.5 \mathrm{U} / \mu \mathrm{L}), 2 \mu \mathrm{L}$ DNA (10-20 ng), and $8 \mu \mathrm{L}$ of distilled water. The cycling profile started with an initial denaturation of template DNA at $94{ }^{\circ} \mathrm{C}$ for $5 \mathrm{~min}$, followed by 35 cycles of $94{ }^{\circ} \mathrm{C}$ for $30 \mathrm{~s}$, annealing at $64{ }^{\circ} \mathrm{C}$ for $30 \mathrm{~s}$, elongation at $72{ }^{\circ} \mathrm{C}$ for $30 \mathrm{~s}$, and a single cycle of final elongation at $72{ }^{\circ} \mathrm{C}$ for $5 \mathrm{~min}$. The PCR products were sequenced using the service provided by Apical Scientific Sdn. Bhd. (Seri Kembangan, Malaysia). The 16s rRNA sequences were searched against the National Centre of Biotechnology Information (NCBI) database using the Basic Local Alignment Search Tool (BLAST) (Altschul et al., 1990), and the Ribosomal Database Project (RDP) using the sequence aligner (Q. Wang et al., 2007). The 16s rRNA sequences of all isolates were deposited into the NCBI database with the accession numbers of MN203661 (JBAA132), MN203662 (K2B121), MN203663 (K2B131), MN203664 (K2B421), MN203665 (K2B431), MN203666 (KTP211), MN203667 (KTP231), MN203668 (SNH212), MN203669 (SNH222), MN203670 (SNH231), MN203671 (SNH232), MN203672 (TGB111), MN203673 (TGB112), MN203674 (TGB131). 


\section{Phylogenetic Analysis}

The 16s rRNA sequences of the most significant match for each isolate based on Nucleotide BLAST (BLASTn) were retrieved from NCBI and used for phylogenetic analysis in Molecular Evolutionary Genetics Analysis (MEGA)-X (version 10.2.6) (Kumar et al., 2018). An unweighted pair group method with arithmetic mean (UPGMA) tree (Sneath \& Sokal, 1963) was constructed with 1,500 bootstrap replicates using the Tamura-Nei model (Tamura \& Kumar, 2002) and rooted using Aquaspirillum polymorphum NRBC 13961 (NR_104710.1) as an outgroup. Branches corresponding to partitions reproduced in less than $70 \%$ of bootstrap replicates were collapsed.

\section{Biochemical Characterisation}

The isolate that displayed more than $50 \%$ of in vitro antagonistic activity and defined inhibition pattern was chosen for further characterisation. Next, the nitrogen-fixing test was performed using the methods explained in Baldani et al. (2014). Meanwhile, the phosphate solubilisation test was conducted based on the protocols provided in Chatli et al. (2008). Lastly, the catalase test, cetrimide test, citrate test, decarboxylase test (arginine, lysine), gelatine liquefaction test, indole production, lipase solubilisation test, Methyl Red-Voges Prokaur (MR-VP), nitrate reduction, oxidase test, oxidative-fermentative test (dextrose, inulin, lactose, mannitol, sucrose), and sulphate-indole-motility test were all performed according to the protocols described in Cappuccino and Sherman (2008).

\section{RESULTS AND DISCUSSION}

\section{Isolation, Screening, and Siderophore Production Assay}

A total of 55 soil samples were collected from the immediate vicinity of banana plants. From these samples, 32 fluorescent isolates were obtained. However, only 14 of the fluorescent isolates-KTP231, JBAA132, SNH212, K2B421, TGB112, SNH222, SNH232, TGB131, K2B431, KTP211, TGB111, K2B131, SNH231, and K2B121-were positive for siderophore production. Figure 1 shows the differences observed in control a non-siderophore producer and a siderophore producer. The orange halos surrounding the colonies indicate the presence of siderophores.
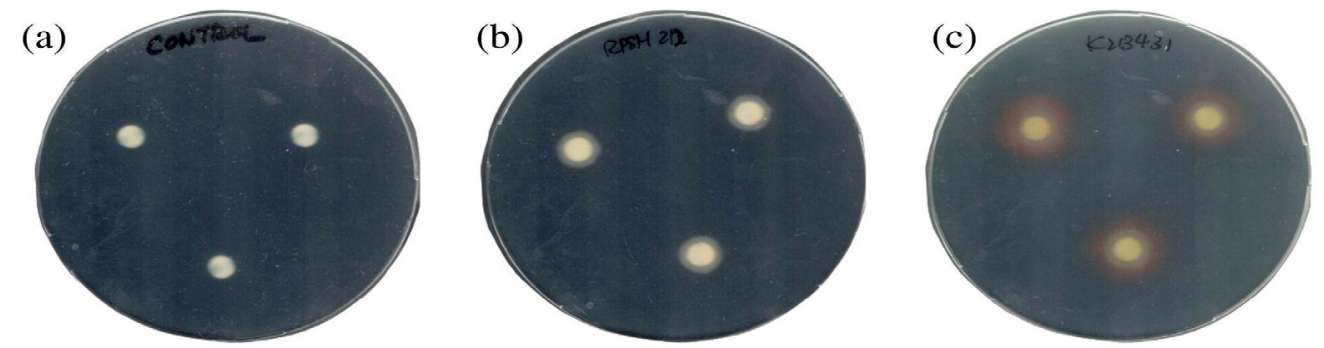

Figure 1. Siderophore production assays. (a) Control plate with uninoculated filter paper discs; (b) plate showing a lack of orange halo around the colonies, thus indicating a non-siderophore producer; (c) plate showing orange halo around colonies, thus indicating a siderophore producer 


\section{In vitro Antagonistic Assay}

The antagonistic ability of the 14 siderophore producers against Foc TR4 was tested on PDA. All 14 isolates demonstrated various inhibition rates after ten days of incubation. Compared to the control plate, inhibitions were observed in all the plates indicated by the halt of mycelial growth towards the bacterial isolates. Figure 2 shows the Foc TR4 mycelial growth in the control plate (a) and cultured with inhibitive isolates (b-o) after ten days of incubation. The inhibition of the mycelial growth can be clearly seen in plates (b) JBAA132, (c) K2B121, (d) K2B131, (e) K2B421, and (h) KTP231. A less defined inhibition zone was observed in all other plates, with plates (m) TGB111 and (o) TGB131 displaying the weakest inhibition abilities. Among the isolates screened, seven isolates showed more than $40 \%$ in vitro inhibition rates. The percentages of inhibition for all 14 isolates were plotted and are shown in Figure 3. One-way ANOVA revealed a significant difference in the inhibition rate $(p<0.0001)$. The Tukey's HSD posthoc test found that the inhibition rates of JBAA132, K2B131, KTP231, SNH212, K2B121, KTP211, SNH232, TGB111, SNH222, TGB112, K2B43, and K2B4211 were significantly different to the control ( $p$ $<0.0001)$. However, there was no significant difference among the isolates except for JBAA132 vs. SNH231 and JBAA132 vs. TGB131.

Antagonistic bacteria play an important role in suppressing soil-borne plant diseases and are potential biocontrol agents. The fungal inhibition efficiency of various bacterial species against Foc has been studied over the years. Li et al. (2012) studied 45 isolates of Pseudomonas spp. and discovered that these isolates demonstrated an inhibition rate that ranged from $38.30 \%$ to $67.14 \%$ against Foc. Meanwhile, Yuan et al. (2012) showed that volatile compounds from Bacillus amyloliquefaciens achieved 30$40 \%$ inhibition in dual culture plates against Foc. Zacky and Ting (2013) discovered that cell and cell-free extracts of Streptomyces griseus produced a $54 \%$ and $33 \%$ rate of inhibition on Foc-TR4. Meanwhile, the usage of Burkholderia cenocepacia in Ho et al. (2014) demonstrated an inhibition rate of 44.4\% against Foc TR4. Similarly, a study by Islam et al. (2018) demonstrated that $P$. aeruginosa BA5 could inhibit Foc growth at a rate of up to $58.33 \%$. It is plausible that isolate JBAA132 shows a comparable inhibition rate at 50.38\% against Foc TR4.

\section{Molecular Identification of Isolates}

Molecular identification of the 14 antagonistic isolates using $16 \mathrm{~S}$ rRNA revealed that all isolates were from the genus Pseudomonas, except for isolates KTP211 and SNH231. Similarity searches against both NCBI and RDP databases returned similar significant matches for each isolate. For example, a BLAST search of the 16s rRNA sequence of isolate JBAA132 showed a $99.48 \%$ similarity to Pseudomonas aeruginosa, followed by Pseudomonas otiditis (98.07\%) and Pseudomonas guezennei (97.96\%). Similarity search against RDP also returned $P$. aeruginosa as the top match but only 
(a)

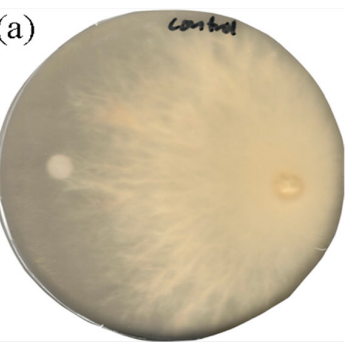

(d)

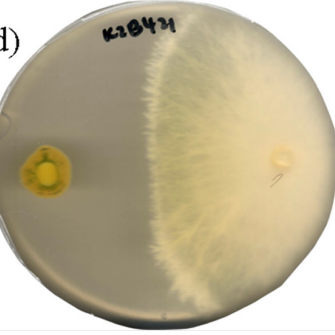

(g)

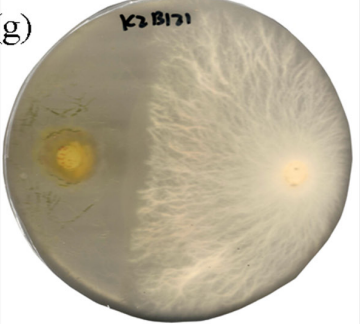

(j)
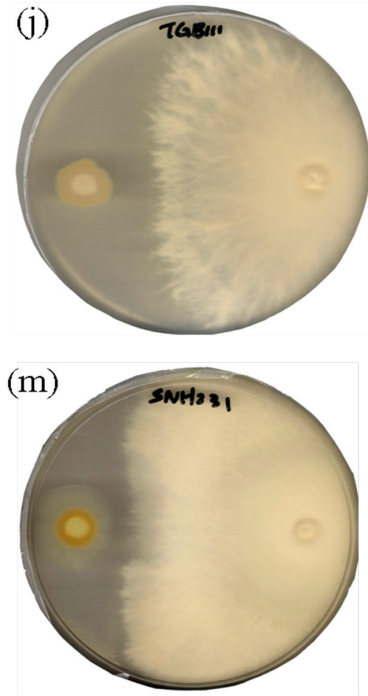

(b)

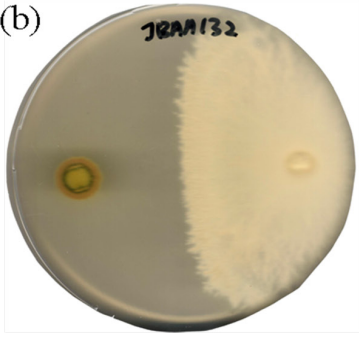

(e)

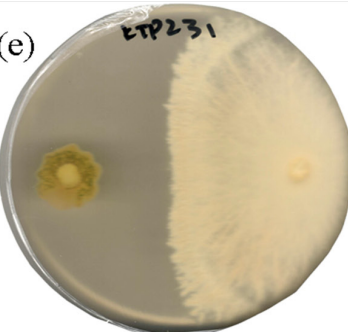

(h)

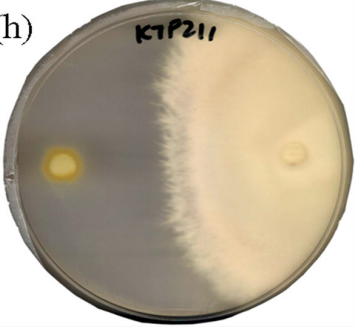

(k)

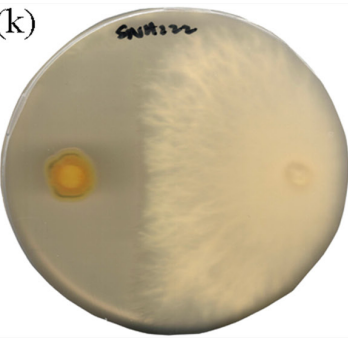

(n)

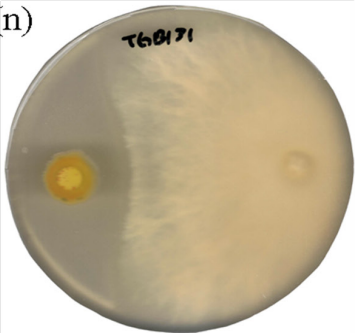

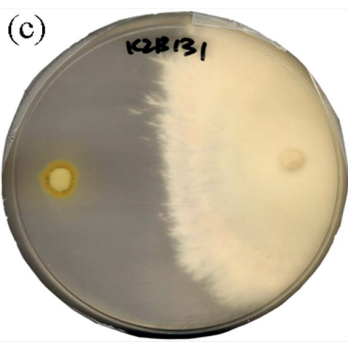

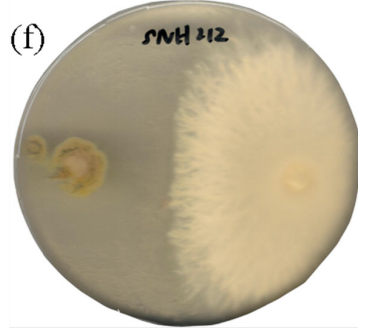

(i)

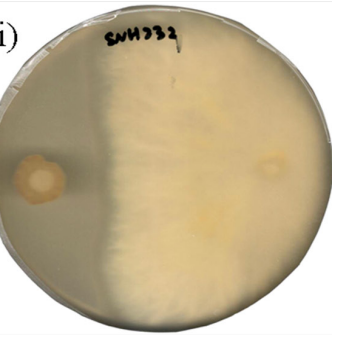

(1)

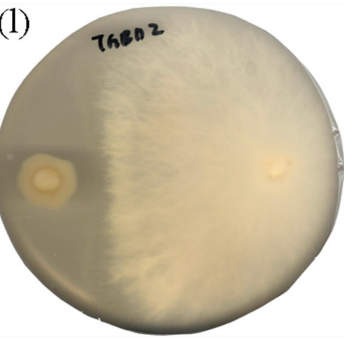

(o)

218421

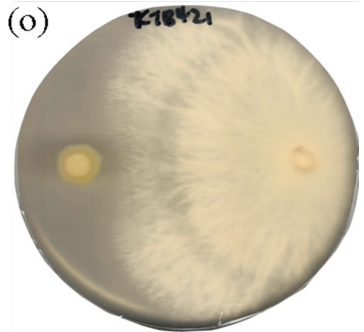

Figure 2. In vitro antagonistic assays. (a) Control with filter paper placed opposite a mycelial plug of Foc TR4; (b) JBAA132; (c) K2B121; (d) K2B131; (e) K2B421; (f) K2B431; (g) KTP211; (h) KTP231; (i) SNH212; (j) SNH222; (k) SNH231; (1) SNH232; (m) TGB111; (n) TGB112; (o) TGB131 


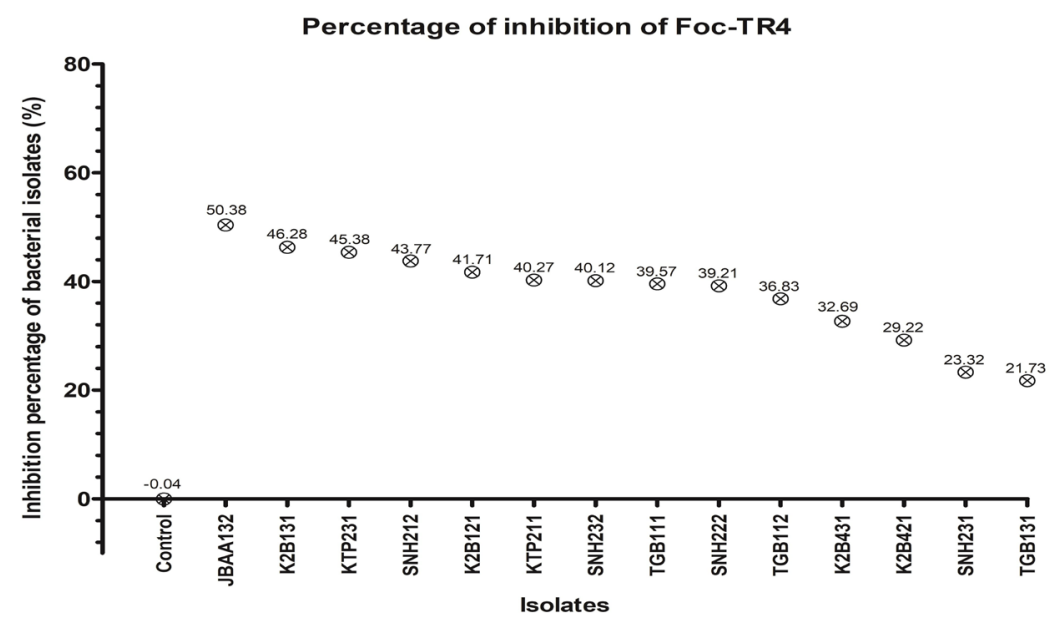

Figure 3. Percentages of inhibition of Foc TR 4 by the 14 bacterial isolates

$87.3 \%$ sequence similarity. The results of molecular identification via $16 \mathrm{~s}$ rRNA based on the two databases are displayed in Table 2 and Table 3.

Ten out of 14 isolates were identified as $P$. aeruginosa, and all matched significantly to type strain DSM50071. While two isolates were identified as Pseudomonas plecoglossicida and Pseudomonas taiwanensis. The abundance of Pseudomonas spp. found in this study collaborated well the findings of Zhou et al. (2019), who reported that Pseudomonas spp. were the third most abundant genus in samples taken from banana rhizospheres. Zhou et al. (2019) also indicated that the top two dominant genera were Bacillus and Lactococcus. However, members of these genera would have likely been screened out by the siderophore production assay in our study. In another study, Kaushal et al. (2020) reported that Pseudomonas spp. was the second most abundant genus in Kilimanjaro revealed by an analysis of soil microbial species around infected and non-infected banana plants. Members from the genera Bacillus, Paenibacillus, Pseudomonas, and Variovorax are often associated with the plant-growth-promoting property. Thus, they are often found in close proximity with numerous plant species (Habibi et al., 2019; Saxena et al., 2020).

In addition to Pseudomonas spp., two non-Pseudomonas siderophore-producing bacteria were also present among the isolates, namely Pantoea septica (isolate KTP211) and Serratia nematodiphila (isolate SNH231). While there have been no reports of Pantoea septica being isolated from the soil surrounding banana plants prior to this study, Walterson and Stavrinides (2015) asserted that some members of the genus Pantoea isolated from soil environments have plant-growth-promoting properties. In another study, Chakdar et al. (2018) discovered a phosphate-solubilising 
soil isolate similar to Pantoea septica the isolates in the study came from the LMG 5345 from termitorial soil in India, genus Pseudomonas and Actinobacter. indicating its plant growth-promoting However, they also identified a bacterial capabilities. Finally, Marcano et al. (2016) isolate that showed a high similarity to studied the bacteria community from the Serratia nematodiphila based on 16s rRNA soil surrounding banana plants. Most of sequencing.

Table 2

Percentages of similarity and coverage of antagonistic isolates capable of inhibition of Foc TR4 based on BLAST search against NCBI database

\begin{tabular}{llcc}
\hline Isolate & BLAST NCBI & $\begin{array}{c}\text { Similarity } \\
(\%)\end{array}$ & $\begin{array}{c}\text { Coverage } \\
(\%)\end{array}$ \\
\hline JBAA132 & Pseudomonas aeruginosa DSM50071 & 99.48 & 99 \\
K2B121 & Pseudomonas aeruginosa DSM50071 & 96.68 & 93 \\
K2B131 & Pseudomonas aeruginosa DSM50071 & 96.51 & 93 \\
K2B421 & Pseudomonas aeruginosa DSM50071 & 100 & 100 \\
K2B431 & Pseudomonas aeruginosa DSM50071 & 97.24 & 91 \\
KTP211 & Pantoea septica LMG 5345 & 99.55 & 100 \\
KTP231 & Pseudomonas plecoglossicida NBRC 103162 & 100 & 100 \\
SNH212 & Pseudomonas aeruginosa DSM50071 & 99.64 & 100 \\
SNH222 & Pseudomonas aeruginosa DSM50071 & 99.82 & 100 \\
SNH231 & Serratia nematodiphila DZ0503SBS1 & 99.56 & 100 \\
SNH232 & Pseudomonas aeruginosa DSM50071 & 99.91 & 100 \\
TGB111 & Pseudomonas taiwanensis BCRC 17751 & 98.35 & 93 \\
TGB112 & Pseudomonas aeruginosa DSM50071 & 96.84 & 89 \\
TGB131 & Pseudomonas aeruginosa DSM50071 & 99.91 & 100 \\
\hline
\end{tabular}

Table 3

Percentage of similarity of antagonistic isolates capable of inhibition of Foc TR4 based on similarity search against the database of Ribosomal Database Project (RDP)

\begin{tabular}{llc}
\hline Isolate & RDP & Similarity (\%) \\
\hline JBAA132 & Pseudomonas aeruginosa DSM50071 & 87.3 \\
K2B121 & Pseudomonas aeruginosa DSM50071 & 96.7 \\
K2B131 & Pseudomonas aeruginosa DSM50071 & 80.5 \\
\hline
\end{tabular}


Table 3 (Continue)

\begin{tabular}{llc}
\hline Isolate & RDP & Similarity (\%) \\
\hline K2B421 & Pseudomonas aeruginosa DSM50071 & 99.6 \\
K2B431 & Pseudomonas aeruginosa DSM50071 & 87.1 \\
KTP211 & Pantoea septica LMG 5345 & 97 \\
KTP231 & Pseudomonas plecoglossicida FPC951 & 99.8 \\
SNH212 & Pseudomonas aeruginosa DSM50071 & 97.7 \\
SNH222 & Pseudomonas aeruginosa DSM50071 & 98.3 \\
SNH231 & Serratia nematodiphila DZ0503SBS1 & 98 \\
SNH232 & Pseudomonas aeruginosa DSM50071 & 99.3 \\
TGB111 & Pseudomonas taiwanensis BCRC 17751 & 85.2 \\
TGB112 & Pseudomonas aeruginosa DSM50071 & 96.7 \\
TGB131 & Pseudomonas aeruginosa DSM50071 & 99 \\
\hline
\end{tabular}

\section{Phylogenetic Analysis}

The phylogenetic tree inferred from the 16S rRNA sequences showed clustering of isolates and species (Figure 4) congruent with the similarity search results. Two main clades were formed, where one of the clades (I) consisted of only Pseudomonas spp. In contrast, the other clade comprised only non-Pseudomonas species (II). The ten isolates (i.e., JBAA132, K2B121, K2B131, K2B421, K2B431, SNH212, SNH222, SNH232, TGB112, and TGB131) identified as $P$. aeruginosa based on BLAST similarity searches were grouped with various Pseudomonas spp. into a clade with a strong bootstrap value indicating genetic closeness. While isolate KTP231 identified as $P$. plecoglossicida and TGB111 identified as P. taiwanensis based on similarity searches, were clustered in the same subclade with several other Pseudomonas spp., which also included $P$. plecoglossicida and $P$. taiwanensis, with a strong bootstrap value of $98 \%$. Meanwhile, isolate KTP211 was placed in the same subclade with Pantoea septica. In contrast, isolate $\mathrm{SNH} 231$, identified as Serratia nematodiphila, was clustered together with Serratia marcescens and Serratia nematodiphila with a strong bootstrap value of $100 \%$.

Among the 14 fluorescent siderophoreproducing isolates capable of inhibiting Foc TR4, 12 were identified as Pseudomonas spp. i.e., $P$. aeruginosa, $P$. plecoglossicida, and P. taiwanensis. Isolate JBAA132, the only isolate that displayed an in vitro inhibitive activity of more than $50 \%$ against Foc TR4 in this study, was identified as P. aeruginosa. Pseudomonas spp. are ubiquitous (Wu et al., 2015) and have been isolated from many environmental samples such as soil (AL-Saleh \& Akbar, 2015) and water (Nasreen et al., 2015). Pseudomonas aeruginosa is a common soil bacterium 


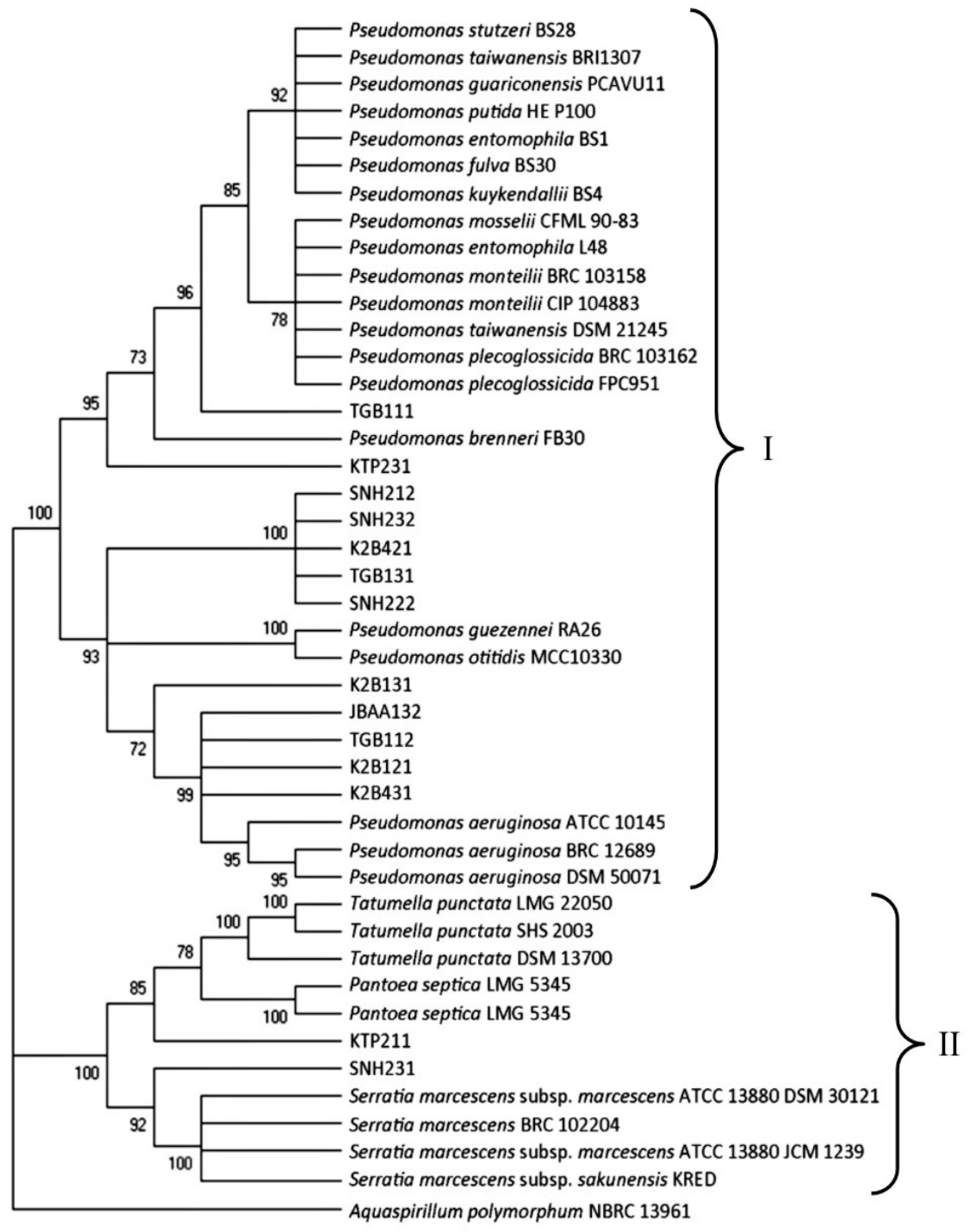

Figure 4. UPGMA tree constructed with MEGA-X using the Tamura-Nei model with 1,500 bootstraps and rooted using Aquaspirillum polymorphum NRBC 13961

(Gupta et al., 1999) that has been studied extensively and was reported to have biocontrol properties. Sekhar and Thomas (2015) discovered that $P$. aeruginosa was one of the bacteria capable of antagonistic ability against Foc. In addition, Lahkar et al. (2015) revealed the ability of the strain JS29 to inhibit the growth of Alternaria solani, the causal agent of tomato blight, by $73 \%$. Meanwhile, P. aeruginosa ID 4365 and SBC 5 were demonstrated to have good antifungal ability against Sclerotium rolfsii, 
the causal agent of Southern blight on vegetables and melons (Rane et al., 2008).

Other species within the same genus, isolate KTP231 (identified as $P$. plecoglossicida) and isolate TGB111 (identified as $P$. taiwanensis), showed moderate inhibitive activity (39.57\%$45.38 \%$ ) against the growth of Foc TR4 in this study. Pseudomonas plecoglossicida was first isolated from cultured ayu or sweetfish (Plecoglossus altivelis) by Nishimori et al. (2000). It was identified as a potential bioremediation agent for hazardous compounds (Boricha \& Fulekar, 2009) but has not been assessed for biocontrol ability prior to this. Pseudomonas taiwanensis is a Pseudomonas species recently isolated from soil (L.-T. Wang et al., 2010). Previous studies revealed that $P$. taiwanensis is a potential biocontrol agent against plant pathogens such as Xanthomonas axonopodis pv. dieffenbachiae (Dhanya et al., 2020), and Xanthomonas oryzae pv. oryzae (Chen et al., 2016). However, no study has investigated the antagonistic activity of $P$. taiwanensis against Foc TR4.

Among the inhibitive isolates, P. septica and $S$. nematodiphila were the only two non-Pseudomonas spp. identified. Thus far, $P$. septica has never been investigated for or associated with biocontrol properties. Interestingly, isolate KTP211 (identified as $P$. septica) exhibited antagonistic activity against Foc TR4 with a moderate in vitro inhibition rate of $40.27 \%$ in this study. On the contrary, based on the low inhibition activity (23.32\%) observed in isolate SNH231 (S. nematodiphila), it is unlikely a potential biocontrol agent against Foc TR4. Nonetheless, Khoa et al. (2016) had demonstrated the biocontrol properties of this species against other plant diseases such as the bacterial leaf blight in rice.

\section{Biochemical Characterisation}

Biochemical assays showed that isolate JBAA132 was catalase-positive and oxidasepositive. It demonstrated the ability to utilise citrate and mannitol and was also positive for gelatinase, tryptophanase, and cysteine desulfurase. The isolate also produced a bright green colour typical of the genus Pseudomonas when cultured on cetrimide agar. Isolate JBAA132 could fix nitrogen and solubilise phosphorus but could not decarboxylate arginine, asparagine, and glutamine. The results are summarised in Table 4.

There are evident differences in the biochemical characteristics between isolate JBAA132 and the type strain $P$. aeruginosa DSM50071 (Reimer et al., 2019). Type strain DSM50071 is purported to produce arginine, asparagine, and glutamine decarboxylases (Reimer et al., 2019). However, isolate JBAA132 did not produce these three types of decarboxylases. In the oxidative-fermentation test, isolate JBAA132 showed different characteristics from type strain DSM50071. Isolate JBAA132 produced a colour change in the media from green to blue when cultured in lactose and sucrose. The colour change from green to blue in the basal media indicated that even though the bacterial strain could not utilise the substrates, it could break 
down the peptones contained in the basal media into alkaline products that turned the media blue (Hanson, 2008). Furthermore, isolate JBAA132 utilised dextrose under fermentative and mannitol under oxidative conditions, which were not associated with the type strain DSM50071 (Reimer et al., 2019). In addition, isolate JBAA132 was also positive for hydrogen sulphide production, which has not been reported in the type strain. It indicates a likelihood of cysteine desulfurase biosynthesis in isolating JBAA132 (J. Wang et al., 2019).
Differences in the biochemical capabilities signify that isolating JBAA132 may be differ from the type strain DSM50071. This finding is congruent with the similarity results obtained from the search against the RDP, which showed only $87.3 \%$ similarity between isolate JBAA132 and the type strain. In addition, isolate JBAA132 is also capable of phosphorus solubilisation and nitrogen fixation, mechanisms found in most plant-growth-promoting bacteria (Gamalero \& Glick, 2011).

Table 4

Biochemical characterisation of isolate JBAA132 and comparison with available data for Pseudomonas aeruginosa DSM50071

\begin{tabular}{llcc}
\hline Biochemical Test & & JBAA132 & DSM50071 \\
\hline Catalase production & & + & + \\
Cetrimide & & + & + \\
Citrate agar & Arginine & + & + \\
Decarboxylase activity & Asparagine & - & + \\
& Glutamine & - & + \\
& Lysine & - & - \\
& Tyrosine & - & n.a. \\
Gelatine liquefaction & & - & + \\
Indole production & & ++ & - \\
Lipase & & - & n.a. \\
Methyl Red-Voges Prokaur & MR & - & - \\
Nitrate reduction & VP & - & - \\
Nitrogen fixation & & + & + \\
Oxidase production & & + & n.a. \\
\hline
\end{tabular}


Table 4 (Continue)

\begin{tabular}{lcc}
\hline Biochemical Test & JBAA132 & DSM50071 \\
\hline Dextrose Oxidation & $\pm_{\mathrm{b}}$ & + \\
Dextrose Fermentation & + & - \\
Inulin Oxidation & $\pm_{\mathrm{b}}$ & n.a. \\
Inulin Fermentation & - & n.a. \\
Lactose Oxidation & $\pm_{\mathrm{b}}$ & - \\
Lactose Fermentation & - & n.a. \\
Sucrose Oxidation & $\pm_{\mathrm{b}}$ & - \\
Sucrose Fermentation & - & n.a. \\
Mannitol Oxidation & + & - \\
Mannitol Fermentation & - & n.a. \\
Phosphate solubilisation & + & n.a. \\
Motility & + & + \\
Hydrogen Sulphide Production & + & - \\
\hline
\end{tabular}

Note. a indicates very rapid liquefaction of gelatine, whereas ${ }_{\mathrm{b}}$ indicates the production of alkaline products. n.a. indicates that no information regarding this test is available at present

\section{CONCLUSION}

Antagonistic bacteria hold great potential as biocontrol agents in suppressing Foc TR4. In this study, siderophore-producing fluorescent soil isolates of genera Pseudomonas, Pantoea, and Serratia exhibited inhibitive activities against Foc TR4 during in vitro antagonistic assays were isolated. Isolate JBAA132 displayed high inhibition activity against Foc TR4 at a rate of $50.38 \%$. Furthermore, the isolate showed high sequence similarity with P. aeruginosa DSM50071 based on 16s rRNA sequence searched against the NCBI database. However, it only showed $87.3 \%$ of sequence similarity to $P$. aeruginosa DSM50071 when searched against RDP.
Furthermore, the isolate also displayed several biochemical characteristics different from type strain DSM50071. These findings indicate that isolating JBAA132 may be a different strain of $P$. aeruginosa. In addition, isolate JBAA132 showed biochemical activities that suggest its potential as a plant growth promoter. Therefore, it is proposed that isolates with more than $40.0 \%$ in vitro inhibition against Foc TR4 may be further explored for their potential in vivo inhibitive abilities. Nonetheless, the pathogenicity of the isolates on the animal must be investigated and determined prior to further in vivo studies. 


\section{ACKNOWLEDGEMENTS}

The Ministry of Higher Education Malaysia funded this work through the Fundamental Research Grant Scheme, project number FRGS/1/2015/ST03/UPM/02/1 (5524803).

\section{REFERENCES}

Agrios, G. N. (2005). Plant diseases caused by fungi. In Plant pathology (5th ed., pp. 385614). Elsevier Academic Press. https://doi. org/10.1016/b978-0-08-047378-9.50017-8

AL-Saleh, E., \& Akbar, A. (2015). Occurrence of Pseudomonas aeruginosa in Kuwait soil. Chemosphere, 120, 100-107. https://doi. org/10.1016/j.chemosphere.2014.06.031

Altschul, S. F., Gish, W., Miller, W., Myers, E. W., \& Lipman, D. J. (1990). Basic local alignment search tool. Journal of Molecular Biology, 215(3), 403-410. https://doi.org/10.1016/S00222836(05)80360-2

Andersson, P. F., Levenfors, J., \& Broberg, A. (2012). Metabolites from Pseudomonas brassicacearum with activity against the pink snow mould causing pathogen Microdochium nivale. BioControl, 57(3), 463-469. https://doi.org/10.1007/s10526011-9411-5

Andrews, S. C., Robinson, A. K., \& RodríguezQuiñones, F. (2003). Bacterial iron homeostasis. FEMS Microbiology Reviews, 27(2-3), 215-237. https://doi.org/10.1016/s0168-6445(03)00055-x

Baldani, J. I., Reis, V. M., Videira, S. S., Boddey, L. H., \& Baldani, V. L. D. (2014). The art of isolating nitrogen-fixing bacteria from nonleguminous plants using $\mathrm{N}$-free semi-solid media: A practical guide for microbiologists. Plant and Soil, 384(1-2), 413-431. https://doi. org/10.1007/s11104-014-2186-6

Boricha, H., \& Fulekar, M. (2009). Pseudomonas plecoglossicida as a novel organism for the bioremediation of cypermethrin. Biology and Medicine, 1(4), 10.
Budzikiewicz, H. (1996). Siderophores from fluorescent Pseudomonas. In Atta-ur-Rahman (Ed.), Studies in natural products chemistry (Vol. 19, pp. 793-835). Elsevier. https://doi. org/10.1016/s1572-5995(96)80019-6

Cappuccino, J. G., \& Sherman, N. (2008). Microbiology: A laboratory manual (8th ed.). Pearson Education.

Chaiharn, M., Chunhaleuchanon, S., \& Lumyong, S. (2009). Screening siderophore producing bacteria as potential biological control agent for fungal rice pathogens in Thailand. World Journal of Microbiology and Biotechnology, 25(11), 1919-1928. https://doi.org/10.1007/ s11274-009-0090-7

Chakdar, H., Dastager, S. G., Khire, J. M., Rane, D., \& Dharne, M. S. (2018). Characterization of mineral phosphate solubilizing and plant growth promoting bacteria from termite soil of arid region. 3 Biotech, $8(11), 463$. https://doi. org/10.1007/s13205-018-1488-4

Chatli, A. S., Beri, V., \& Sidhu, B. S. (2008). Isolation and characterisation of phosphate solubilising microorganisms from the cold desert habitat of Salix alba Linn. in trans Himalayan region of Himachal Pradesh. Indian Journal of Microbiology, 48(2), 267-273. https://doi. org/10.1007/s12088-008-0037-y

Chen, W.-J., Kuo, T.-Y., Hsieh, F.-C., Chen, P.-Y., Wang, C.-S., Shih, Y.-L., Lai, Y.-M., Liu, J.-R., Yang, Y.-L., \& Shih, M.-C. (2016). Involvement of type VI secretion system in secretion of iron chelator pyoverdine in Pseudomonas taiwanensis. Scientific Reports, 6(1), 32950. https://doi.org/10.1038/srep32950

Cornelis, P., \& Matthijs, S. (2007). Pseudomonas siderophores and their biological significance. In A. Varma \& S. B. Chincholkar (Eds.), Soil biology (Vol. 12, pp. 193-203). Springer-Verlag. https://doi.org/10.1007/978-3-540-71160-5_9 
Dhanya, S., Sherin, V., Divya, K., Sreekumar, J., \& Jisha, M. S. (2020). Pseudomonas taiwanensis (MTCC11631) mediated induction of systemic resistance in Anthurium andreanum L. against blight disease and visualisation of defence related secondary metabolites using confocal laser scanning microscopy. Biocatalysis and Agricultural Biotechnology, 24, 101561. https:// doi.org/10.1016/j.bcab.2020.101561

Dita, M., Barquero, M., Heck, D., Mizubuti, E. S. G., \& Staver, C. P. (2018). Fusarium wilt of banana: Current knowledge on epidemiology and research needs toward sustainable disease management. Frontiers in Plant Science, 9, 1468. https://doi.org/10.3389/fpls.2018.01468

Food and Agriculture Organization of the United Nations. (2019). Food outlook - Biannual report on global food markets. FAO. https://doi. org/10.1787/agr_outlook-2019-en

Gamalero, E., \& Glick, B. R. (2011). Mechanisms used by plant growth-promoting bacteria. In D. K. Maheshwari (Ed.), Bacteria in agrobiology: Plant nutrient management (pp. 17-46). Springer. http://dx.doi.org/10.1007/978-3-64221061-7_2

Ghag, S. B., Shekhawat, U. K. S., \& Ganapathi, T. R. (2015). Fusarium wilt of banana: Biology, epidemiology and management. International Journal of Pest Management, 61(3), 250-263. https://doi.org/10.1080/09670874.2015.1043972

Gupta, C. P., Sharma, A., Dubey, R. C., \& Maheshwari, D. K. (1999). Pseudomonas aeruginosa (GRC1) as a strong antagonist of Macrophomina phaseolina and Fusarium oxysporum. Cytobios, 99(392), 183-189.

Habibi, S., Djedidi, S., Ohkama-Ohtsu, N., Sarhadi, W. A., Kojima, K., Rallos, R. V., Ramirez, M. D. A., Yamaya, H., Sekimoto, H., \& Yokoyama, T. (2019). Isolation and screening of indigenous plant growth-promoting rhizobacteria from different rice cultivars in Afghanistan soils.
Microbes and Environments, 34(4), 347-355. https://doi.org/10.1264/jsme2.ME18168

Hanson, A. (2008). Oxidative-fermentative test protocol. https://web.archive.org/ web/20111014202803/http://www. microbelibrary.org/component/resource/ laboratory-test/3151-oxidative-fermentativetest-protocol

Hennessy, C., Walduck, G., Daly, A., \& Padovan, A. (2005). Weed hosts of Fusarium oxysporum $\mathrm{f}$. sp. cubense tropical race 4 in northern Australia. Australasian Plant Pathology, 34(1), 115-117. https://doi.org/10.1071/ap04091

Ho, Y.-N., Chiang, H.-M., Chao, C.-P., Su, C.C., Hsu, H.-F., Guo, C., Hsieh, J.-L., \& Huang, C.-C. (2014). In planta biocontrol of soilborne Fusarium wilt of banana through a plant endophytic bacterium, Burkholderia cenocepacia 869T2. Plant and Soil, 387(1-2), 295-306. https://doi.org/10.1007/s11104-0142297-0

Islam, Md. A., Nain, Z., Alam, Md. K., Banu, N. A., \& Islam, Md. R. (2018). In vitro study of biocontrol potential of rhizospheric Pseudomonas aeruginosa against Fusarium oxysporum f. sp. cucumerinum. Egyptian Journal of Biological Pest Control, 28(1), 90. https://doi.org/10.1186/ s41938-018-0097-1

Jayaraj, J., Parthasarathi, T., \& Radhakrishnan, N. V. (2007). Characterization of a Pseudomonas fluorescens strain from tomato rhizosphere and its use for integrated management of tomato damping-off. BioControl, 52(5), 683-702. https://doi.org/10.1007/s10526-006-9046-0

Jenny, M., \& Kingsbury, J. (2018). Properties and prevention: A review of Pseudomonas aeruginosa. Journal of Biology and Medical Research, 2(3), 18.

Kaushal, M., Swennen, R., \& Mahuku, G. (2020). Unlocking the microbiome communities of banana (Musa spp.) under disease stressed 
(Fusarium wilt) and non-stressed conditions. Microorganisms, 8(3), 443. https://doi. org/10.3390/microorganisms 8030443

Khoa, N. Đ., Giàu, N. Đ. N., \& Tuấn, T. Q. (2016). Effects of Serratia nematodiphila CT-78 on rice bacterial leaf blight caused by Xanthomonas oryzae pv. oryzae. Biological Control, 103, 1-10. https://doi.org/10.1016/j.biocontrol.2016.07.010

Kumar, S., Stecher, G., Li, M., Knyaz, C., \& Tamura, K. (2018). MEGA X: Molecular evolutionary genetics analysis across computing platforms. Molecular Biology and Evolution, 35(6), 15471549. https://doi.org/10.1093/molbev/msy096

Lahkar, J., Borah, S. N., Deka, S., \& Ahmed, G. (2015). Biosurfactant of Pseudomonas aeruginosa JS29 against Alternaria solani: The causal organism of early blight of tomato. BioControl, 60(3), 401411. https://doi.org/10.1007/s10526-015-9650-y

Li, P., Ma, L., Feng, Y. L., Mo, M. H., Yang, F. X., Dai, H. F., \& Zhao, Y. X. (2012). Diversity and chemotaxis of soil bacteria with antifungal activity against Fusarium wilt of banana. Journal of Industrial Microbiology and Biotechnology, 39(10), 1495-1505. https://doi.org/10.1007/ s10295-012-1163-4

Liao, C. H. (2006). Pseudomonas and related genera. In C. de W. Blackburn (Ed.), Food spoilage microorganisms (pp. 507-540). Woodhead Publishing Limited. https://doi. org/10.1533/9781845691417.5.507

Marcano, I.-E., Díaz-Alcántara, C.-A., Urbano, B., \& González-Andrés, F. (2016). Assessment of bacterial populations associated with banana tree roots and development of successful plant probiotics for banana crop. Soil Biology and Biochemistry, 99, 1-20. https://doi.org/10.1016/j. soilbio.2016.04.013

Nasiri, H., Forouzandeh, M., Rasaee, M. J., \& Rahbarizadeh, F. (2005). Modified salting-out method: High-yield, high-quality genomic DNA extraction from whole blood using laundry detergent. Journal of Clinical Laboratory Analysis, 19(6), 229-232. https://doi. org/10.1002/jcla.20083

Nasreen, M., Sarker, A., Malek, M. A., Ansaruzzaman, Md., \& Rahman, M. (2015). Prevalence and resistance pattern of Pseudomonas aeruginosa isolated from surface water. Advances in Microbiology, 5(1), 74-81. https://doi. org/10.4236/aim.2015.51008

Nawangsih, A. A., \& Purba, F. (2013). Isolation of fluorescent pseudomonads, heat tolerant and chitinolytic bacteria in banana rhizosphere with antagonistic activities against Fusarium oxysporum f. sp. cubense in vitro and molecular identification of selected isolates. International Society for Southeast Asian Agricultural Sciences, 19(2), 30-40.

Nishimori, E., Kita-Tsukamoto, K., \& Wakabayashi, H. (2000). Pseudomonas plecoglossicida sp. nov., the causative agent of bacterial haemorrhagic ascites of ayu, Plecoglossus altivelis. International Journal of Systematic and Evolutionary Microbiology, 50(1), 83-89. https://doi.org/10.1099/00207713-50-1-83

Pérez-Miranda, S., Cabirol, N., George-Téllez, R., Zamudio-Rivera, L. S., \& Fernández, F. J. (2007). O-CAS, a fast and universal method for siderophore detection. Journal of Microbiological Methods, 70(1), 127-131. https://doi.org/10.1016/j.mimet.2007.03.023

Ploetz, R. C. (2005). Panama disease: An old nemesis rears its ugly head: Part 1 . The beginnings of the banana export trades. Plant Health Progress, 6(1), 18. https://doi.org/10.1094/PHP-20051221-01-RV

ProMusa. (n.d.). Fusarium wilt of banana. http://www. promusa.org/Fusarium+wilt

Rane, M. R., Sarode, P. D., Chaudhari, B. L., \& Chincholkar, S. B. (2008). Exploring antagonistic metabolites of established biocontrol agent of marine origin. Applied Biochemistry and 
Biotechnology, 151(2-3), 665-675. https://doi. org/10.1007/s12010-008-8288-y

Reimer, L.C., Vetcininova, A., Carbasse J. S., Sohngen, C., Gleim, D., Ebeling, C. \& Overmann, J. (2019). BacDive in 2019: Bacterial phenotypic data for High-throughput biodiversity analysis. Nucleic Acids Research, 47(D1), D631-D636. https://doi.org/10.1093/nar/gky879

Sang, M. K., \& Kim, K. D. (2014). Biocontrol activity and root colonization by Pseudomonas corrugata strains CCR04 and CCR80 against Phytophthora blight of pepper. BioControl, 59(4), 437-448. https://doi.org/10.1007/s10526-014-9584-9

Saxena, A. K., Kumar, M., Chakdar, H., Anuroopa, N., \& Bagyaraj, D. J. (2020). Bacillus species in soil as a natural resource for plant health and nutrition. Journal of Applied Microbiology, 128(6), 1583-1594. https://doi.org/10.1111/ jam. 14506

Sayyed, R. Z., \& Patel, P. R. (2011). Biocontrol potential of siderophore producing heavy metal resistant Alcaligenes sp. and Pseudomonas aeruginosa RZS3 vis-à-vis organophosphorus fungicide. Indian Journal of Microbiology, 51(3), 266-272. https://doi.org/10.1007/s12088011-0170-x

Scheerer, L., Pemsl, D., Dita, M., Vicente, L. P., \& Staver, C. (2018). A quantified approach to projecting losses caused by Fusarium wilt Tropical Race 4. Acta Horticulturae, 1196, 211-218. https://doi.org/10.17660/ ActaHortic.2018.1196.26

Schroth, M. N., Cho, J. J., Green, S. K., \& Kominos, S. D. (2018). Epidemiology of Pseudomonas aeruginosa in agricultural areas. Journal of Medical Microbiology, 67(8), 1191-1201. https://doi.org/10.1099/jmm.0.000758

Sekhar, A. C., \& Thomas, P. (2015). Isolation and identification of shoot-tip associated endophytic bacteria from banana cv. Grand Naine and testing for antagonistic activity against Fusarium oxysporum f. sp. cubense. American Journal of Plant Sciences, 06(07), 943-954. https://doi. org/10.4236/ajps.2015.67101

Sharma, M., Tarafdar, A., Ghosh, R., \& Gopalakrishanan, S. (2017). Biological control as a tool for eco-friendly management of plant pathogens. In T. K. Adhya, B. B. Mishra, K. Annapurna, D. K. Verma, \& U. Kumar (Eds.), Advances in soil microbiology: Recent trends and future prospects (Vol. 2, pp. 153-188). Springer Singapore. https://doi.org/10.1007/978-981-107380-9_8

Simeoni, L. A. (1987). Critical iron level associated with biological control of Fusarium wilt. Phytopathology, 77(6), 1057-1061. https://doi. org/10.1094/phyto-77-1057

Sneath, P. H. A., \& Sokal, R. R. (1963). Numerical taxonomy: The principles and practice of numerical classification. W. H. Freeman and Company.

Su, H., Hwang, S., \& Ko, W. (1986). Fusarial wilt of Cavendish bananas in Taiwan. Plant Disease, 70(9), 814-818. https://doi.org/10.1094/pd-70814

Sudarma, I. M., \& Suprapta, D. N. (2011). Diversity of soil microorganisms in banana habitats with and without Fusarium wilt symptom. Journal of International Society for Southeast Asian Agricultural Sciences, 17(1), 147-159.

Tamura, K., \& Kumar, S. (2002). Evolutionary distance estimation under heterogeneous substitution pattern among lineages. Molecular Biology and Evolution, 19(10), 1727-1736. https://doi.org/10.1093/oxfordjournals.molbev. a003995

VanderMolen, G. E., Beckman, C. H., \& Rodehorst, E. (1987). The ultrastructure of tylose formation in resistant banana following inoculation with Fusarium oxysporum f. sp. cubense. Physiological and Molecular Plant Pathology, 31(2), 185-200. https://doi.org/10.1016/08855765(87)90063-4 
Vincent, C., Goettel, M. S., \& Lazarovits, G. (Eds.). (2007). Biological control: A global perspective. Centre for Agriculture and Biosciences International.

Walterson, A. M., \& Stavrinides, J. (2015). Pantoea: Insights into a highly versatile and diverse genus within the Enterobacteriaceae. FEMS Microbiology Reviews, 39(6), 968-984. https:// doi.org/10.1093/femsre/fuv027

Wang, J., Guo, X., Li, H., Qi, H., Qian, J., Yan, S., Shi, J., \& Niu, W. (2019). Hydrogen sulfide from cysteine desulfurase, not 3-mercaptopyruvate sulfurtransferase, contributes to sustaining cell growth and bioenergetics in $E$. coli under anaerobic conditions. Frontiers in Microbiology, 10, 2357. https://doi.org/10.3389/ fmicb.2019.02357

Wang, L.-T., Tai, C.-J., Wu, Y.-C., Chen, Y.-B., Lee, F.-L., \& Wang, S.-L. (2010). Pseudomonas taiwanensis sp. nov., isolated from soil. International Journal of Systematic and Evolutionary Microbiology, 60(9), 2094-2098. https://doi.org/10.1099/ijs.0.014779-0

Wang, Q., Garrity, G. M., Tiedje, J. M., \& Cole, J. R. (2007). Naïve Bayesian classifier for rapid assignment of rRNA sequences into the new bacterial taxonomy. Applied and Environmental Microbiology, 73(16), 5261-5267. https://doi. org/10.1128/AEM.00062-07

Wu, W., Jin, Y., Bai, F., \& Jin, S. (2015). Pseudomonas aeruginosa. In Y.-W. Tang, M. Sussman, D. Liu, I. Poxton, \& J. Schwartzman (Eds.), Molecular medical microbiology (pp. 753-767). Elsevier. http://doi.org/10.1016/b978-0-12-3971692.00041-x
Weller, D. M. (2007). Pseudomonas biocontrol agents of soilborne pathogens: Looking back over 30 years. Phytopathology, 97(2), 250-256. https:// doi.org/10.1094/phyto-97-2-0250

Workman, D. (2021). Bananas exports by country 2020. https://www.worldstopexports.com/ bananas-exports-country/

Yuan, J., Raza, W., Shen, Q., \& Huang, Q. (2012). Antifungal activity of Bacillus amyloliquefaciens NJN-6 volatile compounds against Fusarium oxysporum f. sp. cubense. Applied and Environmental Microbiology, 78(16), 59425944. https://doi.org/10.1128/AEM.01357-12

Zacky, F. A., \& Ting, A. S. Y. (2013). Investigating the bioactivity of cells and cell-free extracts of Streptomyces griseus towards Fusarium oxysporum f. sp. cubense race 4. Biological Control, 66(3), 204-208. https://doi. org/10.1016/j.biocontrol.2013.06.001

Zhou, D., Jing, T., Chen, Y., Wang, F., Qi, D., Feng, R., Xie, J., \& Li, H. (2019). Deciphering microbial diversity associated with Fusarium wilt-diseased and disease-free banana rhizosphere soil. BMC Microbiology, 19(1), 161. https://doi. org/10.1186/s12866-019-1531-6

Zuo, C., Deng, G., Li, B., Huo, H., Li, C., Hu, C., Kuang, R., Yang, Q., Dong, T., Sheng, O., \& Yi, G. (2018). Germplasm screening of Musa spp. for resistance to Fusarium oxysporum $\mathrm{f}$. sp. cubense tropical race 4 (Foc TR4). European Journal of Plant Pathology, 151(3), 723-734. https://doi.org/10.1007/s10658-017-1406-3 